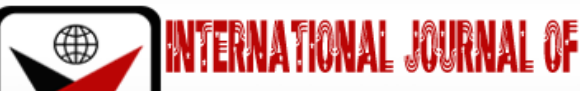

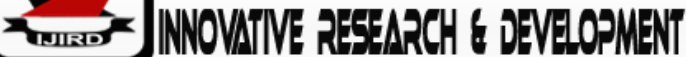

ISSN 2278-0211 (Online)

\section{Certain Foaming Characteristics of Saponins of Leaves of Balanites Aegyptiaca Del}

\author{
Zakariya Hassan Buratai \\ Scientist, Department of Biochemistry, Faculty of Science, \\ University of Maiduguri, Maiduguri, Borno State, Nigeria \\ Oluwole Adebayo Sodipo \\ Professor, Department of Biochemistry, \\ University of Maiduguri, Maiduguri, Borno State, Nigeria
}

\begin{abstract}
:
In this study, the histochemical analysis and phytochemical screening of leaves of Balanites aegyptiaca Del. were conducted to determine the probable presence of saponins. The results revealed the probable presence of saponins and some other secondary metabolites in aqueous, methanol and crude saponins ( $n$-butanol) extracts of the leaves. The yields of the extracts of aqueous, methanol and crude saponins (n-butanol) obtained from the leaves of Balanites aegyptiaca Del. were $19.8 \%, 22.4 \%$ and $2.4 \%$ respectively. The foam heights and foaming times of extracts of the leaves of Balanites aegyptiaca Del. (aqueous, methanol and crude saponins (n-butanol) extracts) and commercial detergents (Triton-X 100 and Tween 80) at concentrations of $0.2 \%, 0.4 \%, 0.5 \%, 0.6 \%, 0.8 \%$, and $1.0 \%$ were subjected to statistical analysis (ANOVA) for comparison of their foam heights and foaming times at 0 min, 1 min, 5 min and $T h r$. The values of aqueous saponins extract were very significant differences $(p<0.01)$, the values of crude saponins (n-butanol) extract as well as commercial detergents (Triton-X 100 and Tween 80 ) were of highly significant differences $(p<0.001)$ while the values of methanol saponins extract were of significant differences $(p<0.05)$ and also all the values of the extracts and commercial detergents solutions were of no significant differences ( $p>0.05$ ). The foaming activities were conducted at concentrations of $0.2 \%, 0.4 \%, 0.5 \%, 0.6 \%, 0.8 \%$ and $1.0 \%$. The foam heights and foaming times increased with increase in concentrations of aqueous solution. Among the three samples Triton-X 100 possessed the highest foam heights and foaming times of $0.5 \%$ with $11.57 \pm 0.51 \mathrm{~cm}$ and $30.73 \pm 0.42 \mathrm{hr}$, followed by Tween 80 with $7.80 \pm 0.22 \mathrm{~cm}$ and $16.98 \pm 0.32 \mathrm{hr}$ and finally crude saponins ( $\mathrm{n}$-butanol) extract with $6.20 \pm 0.25$ $\mathrm{cm}$ and $1.12 \pm 0.06 \mathrm{hr}$. Foam power of $0.5 \%$ crude saponins ( $n$-butanol) extract solution of leaves of Balanites aegyptiaca Del. was $52.7 \%$ of $0.5 \%$ Triton-X 100. Foam power of the $0.5 \%$ crude saponins (n-butanol) extract solution of leaves of Balanites aegyptiaca Del. was $79.4 \%$ of $0.5 \%$ Tween 80 . The R5 values of $27.59 \%, 31.47 \%$ and $25.81 \%$ of aqueous, methanol and crude saponins (n-butanol) extracts respectively represent poor foam stability compared with the values of $90.8 \%$ and $85.3 \%$ of Triton-X 100 and Tween 80 respectively. Therefore, the potentials of using saponins of leaves of Balanites aegyptiaca Del. as stabilizing agents in detergency are poor. However, they may find use in the food and cosmetics industries
\end{abstract}

Keywords: Saponins, foam power, foam stability, balanites aegyptiaca del., triton-X 100, Tween 80

\section{Introduction}

Saponins are phytochemicals found mainly but not exclusively in plants which exhibit foaming characteristics and consist of polycyclic aglycones attached to one or more sugar side chains. The aglycone part, which is also called a sapogenin, is either a steroid $\left(\mathrm{C}_{27}\right)$ or a triterpene $\left(\mathrm{C}_{30}\right)$. The foaming ability of saponins is caused by the combination of a hydrophobic (fat-soluble) sapogenin and a hydrophilic (water-soluble) sugar part. Saponins characteristically have a bitter taste and some are known to be toxic. The number of saccharide chains attached to the sapogenins (aglycones) can vary as can the length of each chain. The saccharide chain length, so far varies from 1 to 11 sugar residues, with the numbers 2-5 being most frequently encountered with both linear and branched chains (4). All saponins have attachment of at least one sugar chain to the aglycone and can be described as mono, di, or tridesmosidic depending on the number of saccharide chains attached to the aglycone. A single sugar chain normally attaches at $\mathrm{C}_{3}$ of aglycone to produce monodesmosidic saponin, while two sugar chains, often attached through ether linkage at $\mathrm{C}_{3}$ and one through ester linkage (acyl glycoside) at $\mathrm{C}_{28}$ (triterpene saponins) or ether linkage at $\mathrm{C}_{26}$ (furostanol saponins) define bidesmosidic saponins. Tridesmosidic saponins have three sugar chains and are usually rare, though a number of these have recently been reported in among others, Astralagus species (Fabaceae) (2)(14), Chenopodium quinoa (Amaranthaceae) (9) and Solidagovirga-aurea (Compositae) (7). Saponins are found in most vegetables, beans and herbs. The most well-known sources are soybeans, peas and some herbs with names that indicate foaming properties, such as soapwort (Saponariaofficinalis, 
Caryophyllaceae), soapberry (Sapindussaponaria, Sapindaceae), soapbark (Quillajasaponaria, Quillajaceae), soaproot (Chlorogalumpomeridianum, Agavaceae), soapnut (Sapindusmukurossi), and soapwood (Clethraoccidentalis, Clethraceae) (4)(10)(9). Commercial saponins are extracted from Quillajasaponaria and Yucca schidigera (Agavaceae).

Balanites aegyptiaca Del. is a multibranched, spiny shrub or tree up to $10 \mathrm{~m}$ high. Crown rounded, dense (but still seen through) with long stout branchlets. Trunk and bark are grey, deeply fissured longitudinally. Leaves compound and spirally arranged on the shoots, dark green with 2 firm coriaceous leaflets; dimensions and shapes varying widely. Petiole canaliculate, from $5 \mathrm{~mm}$ to $20 \mathrm{~mm}$ with a short rachis. Most accounts indicate a maximum length of $8 \mathrm{~mm}$ for Uganda. Margin of each leaflet entire; lamina generally up to $6 \mathrm{~cm}$ long, $4 \mathrm{~cm}$ broad, although apparently smaller $(1-3 \times 0.3-1.5 \mathrm{~cm})$ in the Sahara (Nigeria) and in Palestine. Inflorescence a sessile or shortly pedunculate fascicle of a few flowers. Flower buds ovoid and tomentose. Individual flowers hermaphroditic, pentamerous an actinomorphic, 8-14 $\mathrm{mm}$ in diameter and generally greenish-yellow. Pedicels densely greyish, pubescent and rarely reaching $10 \mathrm{~mm}$ in length, although $15 \mathrm{~mm}$ is reported for Zambia and Zimbabwe. The usual length is about $8 \mathrm{~mm}$. Fruit ellipsoid, up to $4 \mathrm{~cm}$ long and green. Ripe fruit brown or pale brown with a brittle coat enclosing a brown or brown-green sticky pulp and a hardstone seed.

The name Balanites (from the Greek for acorn, referring to the fruit) was given in 1813 by Alire Delile and replaced with Agialid (derived from the Arabic name for the tree, 'heglig') (11).

\section{Materials and Methods}

\subsection{Sample Collection and Treatment}

The sample was collected from the University of Maiduguri campus and authenticated by a plant taxonomist in the Department of Biological Science, University of Maiduguri, Maiduguri, Nigeria. The fresh leaves of Balanites aegyptiaca Del. were heated at $80{ }^{\circ} \mathrm{C}$ for $10 \mathrm{~min}$ and $60{ }^{\circ} \mathrm{C}$ for $30 \mathrm{~min}$ and further drying in air to dryness (8). The dried leaves were ground to powdery form using mortar and pestle as well as electric blender to pass through a $0.3 \mathrm{~mm}$ sieve.

\subsection{Histochemical Analysis}

The fresh leaves of Balanites aegyptiaca Del. were cut into slices and treated with few drops of concentrated sulphuric acid. The series of colour changes were recorded (10).

\subsection{Aqueous Extraction of Saponins}

A $50 \mathrm{~g}$ portion of powdered sample of the leaves of Balanites aegyptiaca Del. was mixed in a conical flask and stirred with $300 \mathrm{ml}$ of distilled water, covered with a thin foil and allowed to stand overnight with occasional shaking for more extraction. The supernatant formed was then carefully decanted into a beaker $(200 \mathrm{ml})$. This process was repeated until the supernatant became clear. The supernatant obtained was dried and residue powdered (6).

\subsection{Methanol Extraction of Saponins}

A $50 \mathrm{~g}$ portion of powdered sample of the leaves of Balanites aegyptiaca Del. was mixed in a conical flask and stirred with $300 \mathrm{ml}$ of methanol covered with a thin foil and allowed to stand overnight with occasional shaking. The supernatant formed was carefully decanted into a beaker. This process was repeated until the supernatant became clear. The supernatant obtained was dried and powdered (6).

\subsection{Crude (n-butanol) Extraction of Saponins}

Saponins were extracted from the leaves of Balanites aegyptiaca Del. by the method suggested by Huang (5) with slight modification. A $100 \mathrm{~g}$ portion of the powdered sample of the leaves of Balanites aegyptiaca Del. was mixed in a conical flask stirred with $500 \mathrm{ml}$ of distilled water covered with a thin foil, heated and shaken for $10 \mathrm{~min}$ and allowed to cool. The supernatant was then decanted carefully into a beaker $(200 \mathrm{ml})$. The process was repeated until the supernatant became colourless. The supernatant was concentrated to about $100 \mathrm{ml}$. The supernatant was then mixed with equal volume of ethyl acetate in a separating funnel, shaken vigorously and kept overnight. The two layers formed were carefully separated (the upper light layer and the lower dark layer). The upper light layer, the ethyl acetate layer was measured and poured back to the separating funnel with equal volume of n-butanol added and kept overnight after vigorous shaken. The n-butanol layer was separated, dried and powdered.

\subsection{Phytochemical Screening} (12) (13).

Phytochemical screening was carried out according to the standard methods of Trease and Evans and Sofowora

\subsection{Foaming Activities}

The various extracts of the leaves of Balanites aegyptiaca Del. used for the determinations of foam-forming activities included: aqueous, methanol, n-butanol (crude saponins), Triton-X 100 and Tween 80 solutions.

\subsection{Foam Heights and Foaming Times of Aqueous, Methanol, n-Butanol (Crude Saponins) Extracts}

Aliquots of $0.1 \mathrm{~g}$ to $0.6 \mathrm{~g}$ of each of the aqueous, methanol, $\mathrm{n}$-butanol (crude saponins) extracts of the leaves of Balanites aegyptiaca Del. were put in the mortar and macerated with $5 \mathrm{ml}$ of distilled water respectively using a pestle. The supernatant formed for each was carefully pipetted into a test tube. The test tubes were shaken with a whirl mixer and 
foam heights measured at initial time (Ho), then after $1 \mathrm{~min}(\mathrm{H} 1)$ and finally $5 \mathrm{~min}(\mathrm{H} 5)$. The times were recorded from the initial time of the formation of foam height to the final time of the disappearance of the foam in hours (T hr) (1).

\subsection{Foam Heights and Foaming Times of Triton-X 100 and Tween 80}

A $0.1 \mathrm{ml}$ to $0.6 \mathrm{ml}$ portions of Triton-X 100 and Tween 80 solutions were measured into the test tubes with $5 \mathrm{ml}$ of distilled water respectively. Each test tube was shaken with a whirl mixer and foam heights measured at initial time (Ho), then after $1 \mathrm{~min}$ (H1) and finally $5 \mathrm{~min}$ (H5). The times were recorded from the initial time of the formation of foam height to the final time of the disappearance of the foam in hours (T hr) (1).

\subsection{Statistical Analysis \\ The data obtained were analyzed using one way analysis of variance (ANOVA) at $p<0.01, p<0.001$ and $p<0.05$ and $\mathrm{p}>0.05$.}

\section{Results and Discussion}

The powder of the leaves of Balanites aegyptiaca Del. $(50 \mathrm{~g})$ was extracted with distilled water (350 $\mathrm{ml})$ and methanol $(250 \mathrm{ml})$ three times each. Crude saponins were extracted successively with ethyl acetate and n-butanol. The yields of the aqueous, methanol and crude saponins (n-butanol) extracts obtained from the leaves of Balanites aegyptiaca Del. were $22.36 \%, 19.80 \%$ and $2.39 \%$ respectively. Solvents play an important role in extraction of saponins. Different solvents have been found to extract different saponins (9).

As shown in Figure 1, foam heights increased with increase in concentrations of aqueous solution. Among the five samples tested, Triton-X 100 had the highest foam height of $11.57 \pm 0.51 \mathrm{~cm}$, followed by Tween 80 with $7.80 \pm 0.22 \mathrm{~cm}$ and crude saponins (n-butanol) extract with $6.20 \pm 0.25 \mathrm{~cm}$. The foam heights of $0.5 \%$ aqueous, methanol and crude saponins (n-butanol) extracts of the leaves of Balanites aegyptiaca Del. were $30.86 \%, 24.72 \%$ and $52.59 \%$ of $0.5 \%$ Triton-X 100 and $79.39 \%, 45.77 \%$ and $36.67 \%$ of $0.5 \%$ Tween 80 . Saponins solutions have been known to have long lasting foam (3).

The foam heights and foaming times of leaves of Balanites aegyptiaca Del. (aqueous, methanol and crude saponins (n-butanol) extracts) including the commercial detergents (Triton-X 100 and Tween 80 ) at varying concentrations of 0.2 $\%, 0.4 \%, 0.5 \%, 0.6 \%, 0.8 \%$ and $1.0 \%$ were subjected to statistical analysis (ANOVA) for comparison. In the comparison of $0 \mathrm{~min}$ with $1 \mathrm{~min}$, the values of aqueous and crude saponins (n-butanol) extracts were of high significant differences $(\mathrm{p}<0.001)$, while those of methanol as well as Triton-X 100 and Tween 80 solutions were of no significant differences ( $p>0.05$ ). In the comparison of $0 \mathrm{~min}$ with $\mathrm{T} \mathrm{hr}$, the values of aqueous and crude saponins (n-butanol) extracts as well as Triton-X 100 and Tween 80 solutions were of high significant differences $(p<0.001)$, methanol extract were of very significant differences $(p<0.01)$ while Triton-X 100 and Tween 80 solutions were of no significant differences $(p>0.05)$. In the comparison of $0 \mathrm{~min}$ with $\mathrm{T} \mathrm{hr}$, the values of aqueous, crude saponins (n-butanol) extracts as well as Triton-X 100 and Tween 80 solutions were of high significant differences $(\mathrm{p}<0.001)$ while those of methanol extract indicated no significant differences ( $p>0.05)$. In the comparison of $1 \mathrm{~min}$ with $\mathrm{T} \mathrm{hr}$, the values of methanol extract as well as Triton-X 100 and Tween 80 solutions were of high significant differences $(\mathrm{p}<0.001)$. Finally, in the comparison of the values of 5 min with $T$ $\mathrm{hr}$, those of aqueous extracts were significantly different $(\mathrm{p}<0.05)$, while those of methanol and crude saponins $(\mathrm{n}$ butanol) extracts showed very significant differences $(\mathrm{p}<0.01)$ and Triton-X 100 and Tween 80 solutions were of high significant differences $(\mathrm{p}<0.001)$. The results of this study showed that $0.5 \%$ of the extracts of the leaves of Balanites aegyptiaca Del. possessed poor foam stability. The rate of weakening of foam defines the stability of the foam (1). Foam with R5 higher than $50 \%$ is reported to be metastable (1). The R5 values of $27.59 \%, 31.47 \%$ and $25.81 \%$ of aqueous, methanol and crude saponins (n-butanol) extracts respectively represent poor foam stability compared with the values of $90.84 \%$ and $85.26 \%$ of Triton-X 100 and Tween 80 respectively.

\begin{tabular}{|c|c|c|}
\hline Test & Plant & Part Result \\
\hline Preliminary & Leaves & +ve \\
\hline \multicolumn{2}{|c|}{ Table 1: Histochemical Analysis of Leaves of Balanites Aegyptiaca Del }
\end{tabular}

Table 1: Histochemical Analysis of Leaves of Balanites Aegyptiaca Del $+v e=$ Series of Colour Changes from Blue-Black to Brown and Finally Dark Brown

\begin{tabular}{|c|c|}
\hline Extract & Yield (\%) \\
\hline Aqueous & 19.80 \\
\hline Methanol & 22.36 \\
\hline Crude Saponins (n-butanol) & 2.39 \\
\hline
\end{tabular}

Table 2: Yields of Extracts of Leaves of Balanites Aegyptiaca Del 


\begin{tabular}{|c|c|c|c|}
\hline \multirow{2}{*}{ Test } & \multicolumn{3}{|c|}{ Results } \\
\cline { 2 - 4 } & Aqueous & Methanol & Crude (n-Butanol) \\
\hline Mayer's & ++ & + & ++ \\
\hline Wagner's & ++ & + & ++ \\
\hline Hager's & + & + & ++ \\
\hline Dragendoff's & ++ & + & + \\
\hline Salkowski's & + & + & - \\
\hline Liebermann-Burchard's & + & + & - \\
\hline Barfoed's & - & + & - \\
\hline Combined Reducing Sugar & + & - & + \\
\hline Fehling's & - & - & - \\
\hline Ketoses & - & - & ++ \\
\hline Molisch's & + & - & + \\
\hline Pentoses & - & + & - \\
\hline Saponins & + & ++ & + \\
\hline Shnoda's & + & - & + \\
\hline Ferric Chloride & - & ++ & - \\
\hline Lead Ethanoate & ++ & ++ & + \\
\hline Sodium Hydroxide & + & - & + \\
\hline Borntrager's & - & + & - \\
\hline Tannins & ++ & + & + \\
\hline Terpenoids & + & + & + \\
\hline Phlobatannins & - & + & + \\
\hline
\end{tabular}

Table 3: Phytochemical Screening of Aqueous, Methanol and Crude

Saponins (N-Butanol) Extract of Leaves of Balanites Aegyptiaca Del

$$
\begin{aligned}
& ++=\text { Presence in moderate concentration } \\
& +\quad=\text { Presence in low concentration } \\
& -\quad=\text { Absent }
\end{aligned}
$$

\begin{tabular}{|c|c|c|c|c|}
\hline \multirow{2}{*}{$\begin{array}{c}\text { Sample } \\
\text { Conc(\%) }\end{array}$} & \multicolumn{3}{|c|}{ Height (cm) } & Time \\
\cline { 2 - 5 } & $\mathbf{0 ~ m i n}$ & $\mathbf{1 ~} \mathbf{~ m i n}$ & $\mathbf{5 ~ m i n}$ & T (hr) \\
\hline 0.2 & $2.48 \pm 0.37^{* * *}$ & $0.37 \pm 0.14$ & $0.22 \pm 0.11$ & \\
\hline 0.4 & $2.48 \pm 0.6$ & $1.47 \pm 0.40^{* *}$ & $0.38 \pm 0.27$ & $0.18 \pm 0.05$ \\
\hline 0.5 & $3.19 \pm 0.59$ & $1.77 \pm 0.33$ & $0.88 \pm 0.30$ & $0.17 \pm 0.05^{* * *}$ \\
\hline 0.6 & $3.57 \pm 0.56$ & $2.12 \pm 0.25$ & $1.38 \pm 0.33$ & $0.16 \pm 0.04$ \\
\hline 0.8 & $3.60 \pm 0.54$ & $1.72 \pm 0.21^{* *}$ & $1.17 \pm 0.18$ & $1.18 \pm 0.05$ \\
\hline 1.0 & $3.68 \pm 0.45$ & $1.48 \pm 0.52$ & $0.78 \pm 0.17$ & $0.06 \pm 0.06^{* * *}$ \\
\hline
\end{tabular}

Table 4: Foam Heights and Foaming Times of Aqueous Extract of Leaves of

Balanites Aegyptiaca Del. at Varying Concentrations

Data are expressed as Mean $\pm S D$ of six determinations

**Significantly Different at $p>0.05$

***Significantly Different at $p<0.001$

\begin{tabular}{|c|c|c|c|c|}
\hline \multirow{2}{*}{$\begin{array}{c}\text { Sample } \\
\text { Conc (\%) }\end{array}$} & \multicolumn{3}{|c|}{ Height (cm) } & Time \\
\cline { 2 - 4 } & $\mathbf{0 ~} \mathbf{~ m i n}$ & $\mathbf{1} \mathbf{~ m i n}$ & $\mathbf{5 ~ m i n}$ & T (hr) \\
\hline 0.2 & $1.33 \pm 0.24$ & $0.93 \pm 0.18$ & $0.62 \pm 0.17$ & $1.78 \pm 0.22$ \\
\hline 0.4 & $2.65 \pm 0.33$ & $0.08 \pm 0.14$ & $0.38 \pm 0.08^{* *}$ & $2.60 \pm 1.17$ \\
\hline 0.5 & $2.86 \pm 0.30$ & $1.50 \pm 0.33$ & $0.90 \pm 0.22$ & $2.87 \pm 1.09$ \\
\hline 0.6 & $3.07 \pm 0.27$ & $2.20 \pm 0.32$ & $0.52 \pm 0.36$ & $3.03 \pm 1.01$ \\
\hline 0.8 & $3.32 \pm 0.30$ & $2.47 \pm 0.35^{*}$ & $1.90 \pm 0.18$ & $3.68 \pm 0.57$ \\
\hline 1.0 & $3.27 \pm 0.24$ & $2.30 \pm 0.29$ & $1.58 \pm 0.31$ & $3.07 \pm 0.84^{* *}$ \\
\hline
\end{tabular}

Table 5: Foam Heights and Foaming Times of Methanol Extract of

Leaves of Balanites Aegyptiaca Del. at Varying Concentrations

Data are expressed as Mean $\pm S D$ of six determinations

*Significantly Different at $p<0.05$

**Significantly Different at $p<0.01$ 


\begin{tabular}{|c|c|c|c|c|}
\hline \multirow{2}{*}{$\begin{array}{c}\text { Sample } \\
\text { Conc (\%) }\end{array}$} & \multicolumn{3}{|c|}{ Height (cm) } & Time \\
\cline { 2 - 5 } & $\mathbf{0 ~} \mathbf{~ m i n}$ & $\mathbf{1} \mathbf{~ m i n}$ & $\mathbf{5 ~} \mathbf{~ i n}$ & T (hr) \\
\hline 0.2 & $5.60 \pm 0.23$ & $4.57 \pm 0.18^{* * *}$ & $1.55 \pm 0.11$ & $0.92 \pm 0.09$ \\
\hline 0.4 & $6.70 \pm 0.14$ & $5.02 \pm 0.16$ & $1.55 \pm 0.11$ & $1.01 \pm 0.05$ \\
\hline 0.5 & $6.20 \pm 0.15$ & $5.12 \pm 0.16$ & $1.60 \pm 0.11$ & $1.07 \pm 0.06$ \\
\hline 0.6 & $6.32 \pm 0.15$ & $5.22 \pm 0.15^{* * *}$ & $1.65 \pm 0.11$ & $1.12 \pm 0.06$ \\
\hline 0.8 & $6.48 \pm 0.38$ & $5.17 \pm 0.23$ & $2.12 \pm 0.15$ & $1.21 \pm 0.03^{* * *}$ \\
\hline 1.0 & $6.78 \pm 0.19$ & $5.60 \pm 0.14$ & $1.98 \pm 0.12$ & $1.26 \pm 0.03^{* *}$ \\
\hline
\end{tabular}

Table 6: Foam Heights and Foaming Times of Crude Saponins ( $n$-Butanol) Extract of Leaves of Balanites Aegyptiaca Del. at Varying Concentrations

Data Are Expressed as Mean \pm SD of Six Determinations

**Significantly Different at $p<0.01$

***Significantly Different at $p<0.001$

\begin{tabular}{|c|l|l|l|l|}
\hline \multirow{2}{*}{$\begin{array}{c}\text { Sample } \\
\text { Conc (\%) }\end{array}$} & \multicolumn{3}{|c|}{ Height (cm) } & \multicolumn{1}{c|}{ Time } \\
\cline { 2 - 5 } & $\mathbf{0 ~} \mathbf{~ m i n}$ & $\mathbf{1} \mathbf{~ m i n}$ & $\mathbf{5 ~} \mathbf{~ i n}$ & T (hr) \\
\hline 0.2 & $10.63 \pm 0.34$ & $9.38 \pm 0.51$ & $9.01 \pm 0.59$ & $24.35 \pm 0.56$ \\
\hline 0.4 & $11.38 \pm 0.59$ & $10.42 \pm 0.29$ & $10.10 \pm 0.69$ & $25.06 \pm 0.49^{* * *}$ \\
\hline 0.5 & $11.57 \pm 0.51$ & $10.79 \pm 0.44$ & $10.51 \pm 0.54$ & $30.73 \pm 0.42$ \\
\hline 0.6 & $11.16 \pm 0.44$ & $11.15 \pm 0.34$ & $10.92 \pm 0.39$ & $36.39 \pm 0.42^{* * *}$ \\
\hline 0.8 & $12.00 \pm 0.27$ & $11.92 \pm 0.29$ & $11.50 \pm 0.51$ & $39.13 \pm 0.49$ \\
\hline 1.0 & $12.35 \pm 0.22$ & $11.96 \pm 0.27$ & $11.62 \pm 0.49$ & $41.27 \pm 0.32^{* * *}$ \\
\hline
\end{tabular}

Table 7: Foam Heights and Foaming Times of Triton-X 100at Varying Concentrations Data Are Expressed as Mean \pm SD of Six Determinations ***Significantly Different at $P<0.001$

\begin{tabular}{|c|c|c|c|c|}
\hline \multirow{2}{*}{$\begin{array}{c}\text { Sample } \\
\text { Conc (\%) }\end{array}$} & \multicolumn{3}{|c|}{ Height (cm) } & Time \\
\cline { 2 - 5 } & $\mathbf{0 ~} \mathbf{~ m i n}$ & $\mathbf{1} \mathbf{~ m i n}$ & $\mathbf{5 ~ m i n}$ & T (hr) \\
\hline 0.2 & $6.70 \pm 0.29$ & $5.80 \pm 0.42$ & $5.40 \pm 0.51$ & $15.28 \pm 0.32$ \\
\hline 0.4 & $7.60 \pm 0.25$ & $6.50 \pm 0.44$ & $6.50 \pm 1.00$ & $16.65 \pm 0.56$ \\
\hline 0.5 & $7.80 \pm 0.22$ & $7.05 \pm 0.37$ & $6.65 \pm 0.81$ & $16.98 \pm 0.32^{* * *}$ \\
\hline 0.6 & $8.00 \pm 0.20$ & $7.60 \pm 0.29$ & $6.80 \pm 0.59$ & $17.30 \pm 0.05$ \\
\hline 0.8 & $8.40 \pm 0.54$ & $7.70 \pm 0.29$ & $7.50 \pm 0.39$ & $18.18 \pm 0.69^{* * *}$ \\
\hline 1.0 & $8.60 \pm 0.59$ & $7.50 \pm 0.86$ & $6.80 \pm 0.91$ & $20.70 \pm 0.49^{* * *}$ \\
\hline
\end{tabular}

Table 8: Foam Heights and Foaming Times of Tween 80at Varying Concentrations Data Are Expressed as Mean \pm SD of Six Determinations

***Significantly Different at $P<0.001$

\begin{tabular}{|c|c|c|c|}
\hline Solutions & \multicolumn{2}{|c|}{ Height (cm) } & *R5 \\
\cline { 2 - 4 } Concentration (0.5 \%) & $\mathbf{0 ~} \mathbf{~ m i n}$ & $\mathbf{5} \mathbf{~ m i n}$ & $\mathbf{( \% )}$ \\
\hline Aqueous & $3.19 \pm 0.59$ & $0.88 \pm 0.30$ & 27.59 \\
\hline Methanol & $2.86 \pm 0.30$ & $0.90 \pm 0.22$ & 31.47 \\
\hline Crude (n-Butanol) & $6.20 \pm 0.15$ & $1.60 \pm 0.11$ & 25.81 \\
\hline Triton-X 100 & $11.57 \pm 0.51$ & $10.51 \pm 0.54$ & 90.84 \\
\hline Tween 80 & $7.80 \pm 0.22$ & $6.65 \pm 0.81$ & 85.26 \\
\hline
\end{tabular}

Table 9: Foam Power and Foam Stability of Various Solutions at Initial Time and Five Minutes Data Are Expressed as Mean \pm SD of Six Determinations

*R5 Is the Ratio of Foam Height at 5 Min to That of 0 Min

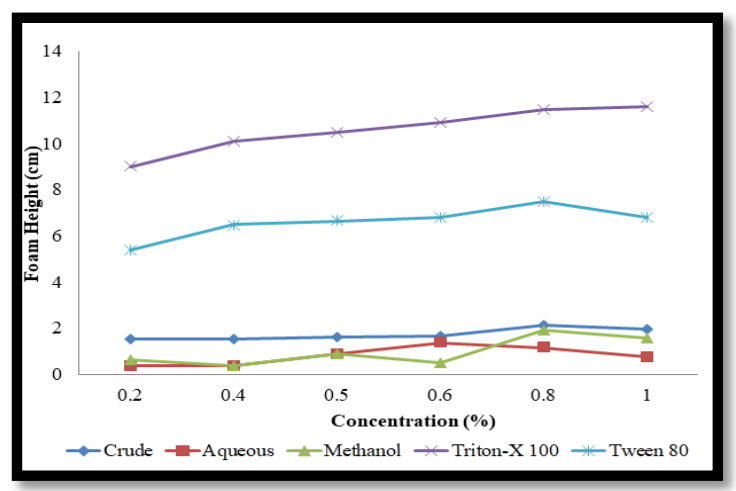

Figure 1: Graph of Foam Power of Various Solutions Data Are Expressed as Mean \pm SD of Six Determinations 


\section{Conclusion}

The results of this study showed that the potentials of using saponins of the leaves of Balanites aegyptiaca Del. as stabilizing agents in detergency are poor. The saponins from this source may be used in food and cosmetics industries.

\section{Acknowledgement}

I acknowledge the effort of my mentor and supervisor Sir Professor Oluwole Adebayo Sodipo of the Department of Biochemistry, University of Maiduguri, Maiduguri, Borno State, Nigeria and President Nigerian Society of Biochemistry and Molecular Biology (NSBMB). And also acknowledge the support of my parents.

\section{References}

i. Chen YF, Yang CH, Chang MS, Ciou YP and Huang, YC (2010). Foam Properties and Detergent Abilities of the Saponins from Camellia oleifera. Int. J. Mol. Sci. 11:4417-4425; doi:10.3390/ijms11114417

ii. Çalis I, Yusofoglu H, Zerbe O, Sticher O Cephalotoside A (1999). A Tridesmosidic Cycloartane Type Glycoside from Astralaguscephalotes var. brevecalys. Phytochemistry, 50: 843-847.

iii. Harborne JB (1984). Phytochemical Methods.A Guide to Modern Techniques of Plant Analysis $2^{\text {nd }}$ Edition. Chapman and Hall Ltd, London,

iv. Hostettmann K, Marston A. (1995) Saponins. Cambridge University Press, Cambridge, New York.

v. Huang HC, Liao SC, Chang FR, Kuo YH and Wu YC (2003). Molluscicidal Saponins from Sapindusmukorossi, Inhibitory Agents of Golden Apple Snails, Pomaceacanaliculata. J. Agric. Food Chem, 51:4916-4919.

vi. Inalegwu B, Sodipo OA (2013). Phytochemical Screening and Haemolytic Activities of Crude and Purified Saponins of Aqueous and Methanolic Extracts of Leaves of Tephrosiavogelli Hook F. Asian Journal of Plant Science and Research, 3(5):7-11

vii. Inose Y, Miyase T, Ueno A (1992). Studies on Constituents of Solidagovirga-aureal. II. Structures of Solidago Saponins. Chem Pharm Bull 40:946-953

viii. Joslyn MM (1970). Methods in food analysis, Academic Press Inc New York, pp. 50-53.

ix. Kim SK (1971), Medical Plant Glycosides. University of Toronto, Toronto, pp.1-9; 49-54.

x. OkoliBE (1982). Field Herbarium and Laboratory Techniques.Rostian 102, Aggrey Road Port-Hacourt pp. 139.

xi. Orwa C, Mutua A, Kindt R, Jamnadass R, Anthony S (2009). Agroforestree Database: A Tree Reference and Selection Guide. Version 4.0 (http://www.worldagroforestry.org/sites/treedbs/treedatabases.asp)

xii. Sofowora A (1993), Screening Plants for Bioactive Agents in Medical Plants and Traditional Medicinal in Africa.

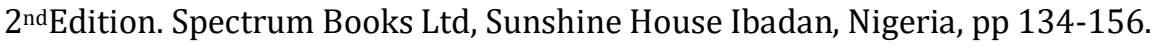

xiii. Trease GE, Evans WC (1996). Textbook of Pharmacogosy, 13 thEdition, Bailler Tindal, London, pp 247-762.

xiv. Yesilada E, Bedir E, Çalis I, Takaishi Y, Ohmoto Y (2005). Effects of Triterpene Saponins from Astralagus Species on In-Vitro Cytokine Release. J. Ethnopharmacol, 96:71-77. 